\title{
Rapidly Mutating Y Chromosomal STRs in Deep-Rooted Endogamous Pedigrees
}

\author{
Shahid Nazir \\ University of Health Sciences \\ Atif Adnan \\ University of Health Sciences \\ Rahat Rehman \\ University of Health Sciences \\ Muhammad Jawad \\ University of Health Sciences
}

Reem Almheiri

Dubai Police General Head Quarters

Reem Lootah

Dubai Police General Head Quarters

Afra Alreyami

Dubai Police General Head Quarters

Iman Almarri

Dubai Police General Head Quarters

Allah Rakha

University of Health Sciences

Sibte Hadi ( $\sim$ shadi@nauss.edu.sa )

Naiff Arab University of Security Sciences

\section{Research Article}

Keywords: Endogamous, Punjab, Pakistan, deep rooted pedigrees, RM Y STRs, Mutation rates

Posted Date: October 14th, 2021

DOI: https://doi.org/10.21203/rs.3.rs-919302/v1

License: (c) (i) This work is licensed under a Creative Commons Attribution 4.0 International License. Read Full License 


\section{Abstract}

Y-chromosome short tandem repeat polymorphisms (Y-STRs) are important in many areas of human genetics. Y chromosomal STRs being normally utilized in the field of forensic exhibit low haplotype diversity in endogamous populations and fail to discriminate among male relatives from same pedigree. Rapidly mutating Y-STRs (RM Y-STRs) have been paid much attention in last decade. These 13 RM Y STRs have high mutation rates (>10-2) and have considerably higher haplotype diversity and discrimination capacity than conventionally used Y-STRs showing remarkable power, when it comes to differentiation in paternal lineages in endogamous populations. Previously, we have analyzed $2-4$ generation, 99 pedigrees covering 1568 pairs of men covering 1-6 meioses from all over Pakistan and 216 male relatives from 18 deep rooted endogamous Sindhi pedigrees covering 1-7 meioses. Here we are presenting 861 pairs of men from 63 endogamous pedigrees covering 1-6 meioses from Punjabi population of Punjab, Pakistan. Mutations were frequently observed at DYF399 and DYF403 while no mutation was observed at DYS526a/b. The rate of differentiation ranged from $29.70 \%$ (first meiosis) to $80.95 \%$ (fifth meiosis) while overall (1 to 6 meiosis) differentiation was $59.46 \%$. Combining previously published data with newly generated data, an overall differentiation rate was $38.79 \%$ based on 5176 pairs of men related by 1-20 meioses, while Y-filer differentiation was $9.24 \%$ based on 3864 pairs. Using father-son pair data from the present and previous studies, we also provide updated RM Y-STR mutation rates.

\section{Introduction}

Y-chromosomal microsatellites or short tandem repeats (Y-STRs) play an important role within forensic genetics ${ }^{1-3}$. Most commonly, Y-STRs are used to determine the male component of DNA mixtures when a high female background is present ${ }^{4,5}$, or to determine paternal relationships between male individuals ${ }^{6-8}$. Currently, a large and growing reference databases exists for estimating Y-STR haplotype frequencies among worldwide human populations (e.g. http://www.yhrd.org or http://usystrdatabase.org/). Commercially available Y-STR kits (Yfiler, Powerplex 23 and Yfiler Plus) are valuable, but they have some limitations for their use in forensic casework. Overall, the haplotype diversities (HD) of these sets of Y STRs are good for outbreeding populations, usually at 0.995 and higher ${ }^{9,10}$. However, the ability to discriminate between individuals is much lower than that of the autosomal STRs. In endogamous populations or populations which run into size contraction followed by quick expansion recently ${ }^{11,12}$, or have particular cultural practices such as patrilocality ${ }^{13,14}$, the currently used Y-STR panels provide limited resolution due to the overall reduced Y-chromosome diversity.

The major drawback of currently used Y-STRs is that they are unable to exclude close or distant patrilineal relatives of the suspect from having deposited the biological material instead of the suspect himself. These STRs maybe helpful in those cases where close or distant male relatives may be involved because of their relatively low mutation rates of only a few mutations per thousand generations per locus ${ }^{6,8,15,16}$.

In 2010, Ballentyne et al ${ }^{16}$ reported mutation rates of 186 Y STRs in 2000 father-son pairs. This study identified 13 Y-STR markers with markedly higher mutation rate of about $10^{2}$ and termed them rapidly mutating (RM) Y-STRs.

In the current study, we have provided empirical evidence of the ability of the 13 RM Y-STRs for improving paternal lineage resolution by analysing 861 pairs of men from 63 endogamous pedigrees covering 1-6 meiosis from Punjab, Pakistan.

\section{Materials And Methods}

\section{Pedigree Samples and DNA Extraction}

Initially 63 pedigrees 1-4 generations consisting of 861 pairs of men were located in different areas of Punjab Pakistan. 327 Blood samples were collected from 63 families. Pedigree of these family members was generated according to their oral records, which were later on confirmed with National Identity Card (NIC). In case of any confusion family registration certificate (FRC) was applied using NADRA (National Database and Registration Authority) online paid services. All participants gave their informed consent either orally (in case they could not write) or in writing, after the study aims and procedures were carefully explained to them. This study was approved by the ethical review board of University of Health Sciences Lahore Pakistan and was in accordance with the principles of the Declaration of Helsinki made at 64th WMA General Assembly, Fortaleza, Brazil, in October 2013. All blood samples were stored at $-20^{\circ} \mathrm{C}$ before DNA extraction. DNA was isolated from blood using ReliaPrep ${ }^{\mathrm{Tm}}$ Blood gDNA Miniprep System (Promega, Madison, USA.) according to the manufacturer's instructions. The quantities of extracted DNA samples were determined using a NanoDrop spectrophotometer (Thermo Scientific, Wilmington DE, USA) and the final concentration of DNA was diluted to 1 to $2 \mathrm{ng} / \mu \mathrm{l}$.

\section{PCR amplification and genotyping}

PCR co-amplification of thirteen rapidly mutating Y-STR loci (DYF387S1, DYF399S1, DYF403S1ab, DYF404S1, DYS449, DYS518, DYS526ab, DYS547, DYS570, DYS576, DYS612, DYS626 and DYS627) were performed in a 5-dye fluorescence-based multiplex reaction using the RM-Yplex assay ${ }^{17}$. From 1 to $2 \mathrm{ng}$ of the target DNA was amplified according to the manufacturer's recommended protocol. Thermal cycling was 
conducted under the following conditions: $95^{\circ} \mathrm{C}$ for $10 \mathrm{~min} ; 20$ cycles of $94^{\circ} \mathrm{C}$ for $30 \mathrm{~s}, 55^{\circ} \mathrm{C}$ for $45 \mathrm{~s}, 72^{\circ} \mathrm{C}$ for $60 \mathrm{~s}$; and a final extension of $72^{\circ} \mathrm{C}$ for $45 \mathrm{~min}$. All loci were amplified in a GeneAmp PCR System 9700 thermal cycler (Applied Biosystems, Foster City, CA). Amplified products were analyzed regarding GS600 LIZ size standard and Allelic Ladder using an ABI 3500 genetic analyzer (Applied Biosystems, Foster City, CA) with the POP-6 ${ }^{\mathrm{TM}}$ polymer (Life Technologies). Samples were analysed using GeneMapper®ID-X software version 1.2 at a threshold of 50 rfu.

\section{Statistical analysis}

Rate of differentiation among male relative pairs were calculated as number of differentiated pairs of relatives by one or more Y STRs divided by the total number of male relative pairs on that particular meiosis or degree of relationship (i.e., pair members separated by 1-20 meiosis). Total numbers of mutations observed dived by number of father-son tested were used to calculate the mutation rates and binomial standard deviation was used to calculate the mutation rates $95 \%$ confidence intervals $(\mathrm{Cl})$ which is available via http://statpages.org/confint.html. Haplotype diversities were calculated as

$$
(n / n-1)\left(1-\sum f i 2\right)
$$

where $n$ is the number of samples, and fi the frequency of the ith haplotype.

\section{Results And Discussion Non-paternity Issues}

The non-paternity events are common in pedigrees and these events were also observed in Pakistani population dataset. To overcome this issue, we split the pedigrees accordingly. In some pedigrees only one individual was involved in non-paternity. After measuring the genetic distance that individual was removed from pedigree. Individuals with mutation event on $\geq 4$ STRs were removed. This threshold was derived from our previous observations based on >2000 father-son pair carrying mutations at three Y-STRs; while none of these showed mutations at more than four Y-STR markers 8,18

\section{Male relative differentiation from current study}

We have analysed the set of 13 RM Y STRs which was described previously 6,15,16,19,20 in 327 Punjabi males belonging to 63 pedigrees 2-4 generations, representing a total of 861 pairs of men related by 1-6 meiosis. Among these 861 pairs, $512(59.46 \%)$ were differentiated by at least one of the 13 RM Y-STR markers (Table 1). More specifically, of the 135, 171, 155, 204, 168, and 28 male relative pairs were separated by 1 (father/ son), 2 (brother, grand-fathers/grand-son), 3 (great grand-fathers/ great grand-son, uncles/nephew), 4 (cousin, grand uncle/ grandnephew), 5 (first cousin once removed) and 6 (second cousin) meioses, respectively. The RM Y-STR set separated 29.7\%, 39.76\%, 60\%, 68.13\%, $80.95 \%$, and $78.57 \%$, pairs respectively. We also noted an increase in relative pair differentiation when there is increased number of meiosis (Table 1). Theoretically, increased differential power of STRs was expected because more chance of mutation events happens at independent meiosis.

Table 1

Male-relative pair differentiation per each of the 13 RM Y-STR markers

\begin{tabular}{|lll|}
\hline Relationship & Total Number of Pairs & Pairs separated by one or more RM Y STRs marker (\%) \\
\hline Father/Son & 135 & $40(29.70 \%)$ \\
\hline Grandfather/Grandson & 67 & $28(41.80 \%)$ \\
\hline Brother/Brother & 104 & $54(51.92 \%)$ \\
\hline Uncle/Son & 147 & $87(59.18 \%)$ \\
\hline Great Grand Father/ Great Grand son & 8 & $6(75 \%)$ \\
\hline 1st Cousin/1st Cousin & 190 & $129(67.90 \%)$ \\
\hline Grand Nephew/ Uncle & 14 & $10(71.42 \%)$ \\
\hline 1st Cousin & 168 & $136(80.95 \%)$ \\
\hline 2nd cousin & 28 & $22(78.57 \%)$ \\
\hline Total & $\mathbf{8 6 1}$ & $\mathbf{5 1 2 ( 5 9 . 4 6 \% )}$ \\
\hline
\end{tabular}

We observed that maximum number of pairs were differentiated based on mutation in multiple markers. 512 pairs were differentiated by at least one of the 13 RM Y-STR markers, 392 (76.56\%) pairs were differentiated by multiple markers. More specifically, of the male relative pairs 
separated by 1 (father/ son), 2 (brother, grandfather/grandson), 3 (great grandfather/ great grandson, uncle/nephew), 4 (cousin, grand uncle/ grandnephew), 5 and 6 meiosis; the 13 RM Y-STR markers set separated 75\%, 71.95\%, 82.80\%, 79.14\%, 72.05\%, and 81.81\%, pairs respectively. Overall, $76.56 \%$ were differentiated by multiple markers. Pairs separated by single-copy markers were only $23.43 \%$ (Table 2 ).

Table 2

Pairs separated by 13 Rapidly mutating Y STRs markers

\begin{tabular}{|c|c|c|c|c|c|}
\hline Relationship & Meioses & $\begin{array}{l}\text { Number } \\
\text { of pairs }\end{array}$ & $\begin{array}{l}\text { Number of pairs } \\
\text { separated by } 13 \text { RM Y- } \\
\text { STRs }\end{array}$ & $\begin{array}{l}\text { Pairs separated by } \\
\text { Multicopy markers (\%) }\end{array}$ & $\begin{array}{l}\text { Pairs separated by single- } \\
\text { copy markers (\%) }\end{array}$ \\
\hline Father/Son & 1 & 135 & 40 & $30(75 \%)$ & $10(25 \%)$ \\
\hline $\begin{array}{l}\text { Grand Father/ Grandson \& } \\
\text { Brother/Brother }\end{array}$ & 2 & 171 & 82 & 59 (71.95\%) & $23(28.05 \%)$ \\
\hline $\begin{array}{l}\text { Great Grand Father,/Great } \\
\text { Grandson \& Uncle/Son }\end{array}$ & 3 & 155 & 93 & 77 (82.80\%) & $16(17.20 \%)$ \\
\hline $\begin{array}{l}\text { 1st cousin/st cousin \& Grand } \\
\text { Nephew/ Uncle }\end{array}$ & 4 & 204 & 139 & 110 (79.14\%) & $29(20.86 \%)$ \\
\hline 5th meioses & 5 & 168 & 136 & 98 (72.05\%) & 38 (27.95\%) \\
\hline 6th meioses & 6 & 28 & 22 & $18(81.81 \%)$ & $4(18.19 \%)$ \\
\hline Overall & & 861 & 512 & $392(76.56 \%)$ & $120(23.43 \%)$ \\
\hline
\end{tabular}

\section{Male relative differentiation from the current and previous studies}

The differentiation rate of $29.7 \%$ using 13 RM Y-STRs for 135 pairs was fairly consistent with those in published in previous studies ${ }^{6,15,20}$. Merging previously published data and newly generated data showed an overall rate of $26.55 \%$ from a total of 2990 pairs (Table 3 ). In current study, we provide an update on male relative differentiation for father-son pairs $(\mathrm{n}=726)$ relative to the previous studies (total $\mathrm{n}=1460){ }^{18-20}$. Combing RM Y-STR data (Table 3), males separated by 2, 3, and 4 meioses are differentiated by $43.69 \%, 52.86 \%$, and $63.22 \%$ which are based on 801,507 , and 533 pairs, respectively. For males separated by 5 and more meioses, we added data for 196 pairs $(5$ th meioses $=168,6$ th meioses $=$ 28). 
Table 3

Combined male relative differentiation rates from the current and previous studies for the RM Y-STR set and the Y-filer Y-STR set

\begin{tabular}{|c|c|c|c|c|}
\hline $\begin{array}{l}\text { Number of } \\
\text { meioses } \\
\text { separating } \\
\text { relative } \\
\text { pairs }\end{array}$ & $\begin{array}{l}\text { Number of } \\
\text { relative } \\
\text { pairs } \\
\text { analyzed } \\
\text { for } \\
\text { RM Y-STRs }\end{array}$ & $\begin{array}{l}\text { Number of male relative pairs separated by one or more of } 13 \text { RM } \\
\text { YSTRs (\%) }\end{array}$ & $\begin{array}{l}\text { Number of } \\
\text { relative } \\
\text { pairs } \\
\text { analyzed } \\
\text { for } \\
\text { Y-filer Y- } \\
\text { STRs }\end{array}$ & $\begin{array}{l}\text { Number of male } \\
\text { relative pairs separated } \\
\text { by one or more of } 17 \\
\text { Yfiler } \\
\text { Y-STRs (\%) }\end{array}$ \\
\hline 1 & 2990 & 794 (26.55\%) & 2474 & $119(4.81 \%)$ \\
\hline 2 & 801 & 350 (43.69\%) & 590 & $62(10.51 \%)$ \\
\hline 3 & 507 & 268 (52.86\%) & 333 & $51(15.32 \%)$ \\
\hline 4 & 533 & 337 (63.22\%) & 318 & 73 (22.95\%) \\
\hline 5 & 231 & 178 (77.05\%) & 63 & $23(36.50 \%)$ \\
\hline 6 & 76 & 56 (73.68\%) & 48 & 18 (37.50\%) \\
\hline 7 & 14 & $4(28.57 \%)$ & 14 & $1(7.14 \%)$ \\
\hline 8 & 7 & $5(71.43 \%)$ & 7 & 1 (14.28\%) \\
\hline 9 & 1 & $1(100 \%)$ & 1 & $1(100 \%)$ \\
\hline 10 & 7 & $6(85.71 \%)$ & 7 & $4(57.14 \%)$ \\
\hline 11 & 6 & $6(100 \%)$ & 6 & $3(50 \%)$ \\
\hline 12 & 0 & 0 & 0 & 0 \\
\hline 13 & 2 & $2(100 \%)$ & 2 & $1(50 \%)$ \\
\hline 14 & 0 & 0 & 0 & 0 \\
\hline 15 & 0 & 0 & 0 & 0 \\
\hline 16 & 0 & 0 & 0 & 0 \\
\hline 17 & 0 & 0 & 0 & 0 \\
\hline 18 & 0 & 0 & 0 & 0 \\
\hline 19 & 0 & 0 & 0 & 0 \\
\hline 20 & 1 & $1(100 \%)$ & 1 & 0 \\
\hline Total & 5176 & 2008 (38.79\%) & 3864 & $357(9.24 \%)$ \\
\hline
\end{tabular}

Hopefully as more data is gathered for RM Y-STRs, these differentiation rates will become more robust, especially for 2 nd degree male relatives (beyond 4th, 5th and 6th meioses).

We have shown this with the differentiation of father-son pairs from the first to the present study. In first study Ballantyne et al. ${ }^{16}$, the rate of differentiation for father-son was $70 \%$ based on 20 pairs. In a follow up Ballantyne et al. study ${ }^{15}$, this rate was decreased to $49 \%$ and number of father son pairs were 39 . The rate of differentiation in the following Ballantyne et al. study ${ }^{21}$ was, further decreased to $27 \%$, where the number of pairs were 2327. In another follow-up Adnan et al. study ${ }^{6}$, the findings were similar with $24 \%$ differentiation rate in 428 pairs. In Rakha et al. study 20 , we analysed 49 pairs with $20.40 \%$ differentiation rate, while $29.70 \%$ of differentiation rate was observed for 135 pairs here. In contrast, Y-filer ${ }^{\text {TM }}$ differentiated $4.81 \%, 10.51 \%, 15.32 \%$ and $22.95 \%$ of related males by $1-4$ meioses based on $2474,590,333$, and 318 pairs studied so far, respectively (Table 3). Nonetheless, conventional Y-STRs tends to have lower mutation rates ${ }^{8,18}$ and $9.24 \%$ of all related males from the combined studies were differentiated with Y-filer as opposed to $38.79 \%$ with RM Y-STRs.

\section{Mutation rate estimates from father-son pairs}

We also have calculated the mutation rates of these rapidly mutating Y-STRs which are based on 135 father-son pairs extracted from the 63 pedigrees, and combined this data with previous studies $6,15,16,20,21$, where the same rapidly mutating Y-STRs panel was implemented for other father-son pairs (Table 4). The mutation rates ranged from $0\left(0-2.70 \times 10^{-2}\right)$ for DYS526a orDYS526b to $1.778 \times 10^{-1}\left(1.174 \times 10^{-1}\right.$ to $2.529 \times$ $10^{-1}$ ) for DYF399S1. The average mutation rate across all $13 \mathrm{RM}$ Y-STR markers was $2.91 \times 10^{-2}$ based on a total number of 59 mutations from 
2025 meioses. Combining this new data with previously available data, the mutation rates ranged from $1.90 \times 10^{-3}\left(7.0 \times 10^{-4}\right.$ to $\left.4.0 \times 10^{-3}\right)$ for DYS626a to $7.45 \times 10^{-2}\left(6.58 \times 10^{-2}\right.$ to $\left.8.39 \times 10^{-2}\right)$ for DYF399S1. These currently estimated mutation rates are most reliable for the 13 RM YSTR markers, given the underlying number of meiosis ranging from 2949 (DYS570) to 3327 (DYF387S1) between markers. The average mutation rate across all $13 \mathrm{RM}$ Y-STR markers was $1.84 \times 10^{-2}\left(1.72 \times 10^{-2}-1.96 \times 10^{-2}\right)$ based on a total number of 878 mutations from 47731 meioses.

Table 4: RM Y STR mutation rates obtained from father-son pairs in the present and previous studies

\begin{tabular}{|c|c|c|c|c|c|c|}
\hline \multirow[b]{2}{*}{ Locus } & \multicolumn{3}{|r|}{ Current Study } & \multicolumn{3}{|r|}{ Combined ${ }^{6,15,20,21}$} \\
\hline & $\begin{array}{c}\text { No. of } \\
\text { mutations }\end{array}$ & Samples & $\begin{array}{l}\text { Mutation Rates ( } 95 \% \text { Confidence } \\
\text { Interval) }\end{array}$ & $\begin{array}{c}\text { No. of } \\
\text { Mutations }\end{array}$ & $\begin{array}{l}\text { Total } \\
\text { Samples }\end{array}$ & $\begin{array}{l}\text { Mutation Rates (95\% Confidence } \\
\text { Interval) }\end{array}$ \\
\hline DYS576 & 4 & 135 & $2.96 \times 10^{-2}\left(8.1 \times 10^{-3}-7.41 \times 10^{-2}\right)$ & 44 & 3250 & $1.35 \times 10^{-2}\left(9.9 \times 10^{-3}-1.81 \times 10^{-2}\right)$ \\
\hline DYF399S1 & 24 & 135 & $\begin{array}{l}1.778 \times 10^{-1}\left(1.174 \times 10^{-1}-2.529 \times 10^{-}\right. \\
\text {1) }\end{array}$ & 247 & 3317 & $7.45 \times 10^{-2}\left(6.58 \times 10^{-2}-8.39 \times 10^{-2}\right)$ \\
\hline DYF387S1 & 5 & 135 & $3.70 \times 10^{-2}\left(1.21 \times 10^{-2}-8.43 \times 10^{-2}\right)$ & 47 & 3327 & $1.41 \times 10^{-2}\left(1.04 \times 10^{-2}-1.87 \times 10^{-2}\right)$ \\
\hline DYS570 & 2 & 135 & $1.48 \times 10^{-2}\left(1.8 \times 10^{-3}-5.25 \times 10^{-2}\right)$ & 32 & 2949 & $1.22 \times 10^{-2}\left(7.40 \times 10^{-3}-1.53 \times 10^{-2}\right)$ \\
\hline DYS526a & 0 & 135 & $0\left(0-2.70 \times 10^{-2}\right)$ & 6 & 3239 & $1.90 \times 10^{-3}\left(7.0 \times 10^{-4}-4.0 \times 10^{-3}\right)$ \\
\hline DYS626 & 2 & 135 & $1.48 \times 10^{-2}\left(1.8 \times 10^{-3}-5.25 \times 10^{-2}\right)$ & 33 & 3212 & $1.03 \times 10^{-2}\left(7.1 \times 10^{-3}-1.44 \times 10^{-2}\right)$ \\
\hline DYS526b & 0 & 135 & $0\left(0-2.70 \times 10^{-2}\right)$ & 38 & 3174 & $1.20 \times 10^{-2}\left(8.50 \times 10^{-3}-1.64 \times 10^{-2}\right)$ \\
\hline DYS627 & 1 & 135 & $7.40 \times 10^{-3}\left(2.0 \times 10^{-4}-4.06 \times 10^{-2}\right)$ & 45 & 3289 & $1.37 \times 10^{-2}\left(1.00 \times 10^{-2}-1.83 \times 10^{-2}\right)$ \\
\hline DYS518 & 5 & 135 & $3.70 \times 10^{-2}\left(1.21 \times 10^{-2}-8.43 \times 10^{-2}\right)$ & 67 & 3079 & $2.18 \times 10^{-2}\left(1.69 \times 10^{-2}-2.76 \times 10^{-2}\right)$ \\
\hline DYS612 & 1 & 135 & $7.40 \times 10^{-3}\left(2.0 \times 10^{-4}-4.06 \times 10^{-2}\right)$ & 60 & 3290 & $1.82 \times 10^{-2}\left(1.39 \times 10^{-2}-2.34 \times 10^{-2}\right)$ \\
\hline DYS449 & 1 & 135 & $7.40 \times 10^{-3}\left(2.0 \times 10^{-4}-4.06 \times 10^{-2}\right)$ & 35 & 3140 & $1.11 \times 10^{-2}\left(7.80 \times 10^{-3}-1.55 \times 10^{-2}\right)$ \\
\hline DYS547 & 3 & 135 & $2.22 \times 10^{-2}\left(4.60 \times 10^{-3}-6.36 \times 10^{-2}\right)$ & 64 & 3202 & $2.00 \times 10^{-2}\left(1.54 \times 10^{-2}-2.54 \times 10^{-2}\right)$ \\
\hline DYF404S1 & 3 & 135 & $2.22 \times 10^{-2}\left(4.60 \times 10^{-3}-6.36 \times 10^{-2}\right)$ & 41 & 3262 & $1.26 \times 10^{-2}\left(9.0 \times 10^{-3}-1.70 \times 10^{-2}\right)$ \\
\hline DYF403S1a & 2 & 135 & $1.48 \times 10^{-2}\left(1.8 \times 10^{-3}-5.25 \times 10^{-2}\right)$ & 80 & 3027 & $2.64 \times 10^{-2}\left(2.10 \times 10^{-2}-3.28 \times 10^{-2}\right)$ \\
\hline DYF403S1b & 6 & 135 & $4.44 \times 10^{-2}\left(1.65 \times 10^{-2}-9.42 \times 10^{-2}\right)$ & 39 & 2974 & $1.31 \times 10^{-2}\left(9.30 \times 10^{-3}-1.79 \times 10^{-2}\right)$ \\
\hline Across $A l l$ & 59 & 2025 & $2.91 \times 10^{-2}\left(2.23 \times 10^{-2}-3.74 \times 10^{-2}\right)$ & 878 & 47731 & $1.84 \times 10^{-2}\left(1.72 \times 10^{-2}-1.96 \times 10^{-2}\right)$ \\
\hline
\end{tabular}

Population genetic analysis in the endogamous Punjabi men

Out of 861 pairs, 75 unrelated Punjabi men, all individuals carried a unique RM Y-STR haplotype with haplotype diversity (HD) 1. In a previous multicenter global study ${ }^{21}$ based on RM Y-STRs where they have reported haplotype diversity of 0.9999985 for almost 12,200 male samples around the globe and for continental regions was ranging from 0.99836 to 0.9999988 . In that multicenter global study ${ }^{21}$, several populations also showed the haplotype diversity of 1 . We also have compared our current results with previously published populations from Pakistan with Yfiler and RM Y-STRs. On Yfiler 17 Y-STRs, British Pakistani ${ }^{22}$, Punjabi population ${ }^{7}$, Kashmiri population ${ }^{7}$, Hazara Population ${ }^{11}$, Sindhi population ${ }^{23}$, Youszai population ${ }^{24}$, and Pathan population ${ }^{25}$ showed DC $99.24 \%, 87.23 \%, 68.3 \%, 76.47 \%, 86.40 \%, 71.92 \%$, and $73.7 \%$, respectively. The samples studied with RM Y-STRs showed HD values ranging from 1 to 0.9921 for Pathan ${ }^{21}$, Brahui ${ }^{21}$, Punjabi ${ }^{21}$, Sindhi ${ }^{21}$, Araein ${ }^{26}$, Pakistani ${ }^{6}$, Punjabi ${ }^{19}$ and Sindhi ${ }^{19}$ populations. Multicenter global study ${ }^{21}$ based RM Y-STRs also reported meaningfully lower haplotype diversities and lower unique haplotype proportions in endogamous ethnic groups than in urban and rural groups ${ }^{21}$. Pakistani population is generally considered highly endogamous, and in our previous study 99 pedigrees were sampled from urban $(\mathrm{N}=48)$ and rural $(\mathrm{N}=$ 51) areas. We didn't observe any effect on RM Y-STR diversity, which may be due to small sample size. In current study 75 pedigrees were sampled from urban $(\mathrm{N}=46)$ and rural $(\mathrm{N}=29)$ areas and again we didn't observe any effect on RM Y-STR diversity.

\section{RM marker differentiation per pairs}

We have calculated the differentiation power of 13 RM Y STRs in 75 pedigrees. On first meiosis 59 pairs were differentiated out of 135 and DYF399S1 differentiated 24 pairs (40.67\%) while DYS526 a/b did not differentiate any pair. This trend was also followed in other pairs where DYF399S1 differentiated most of the pairs while DYS526 a/b did not differentiate any of the pairs (Table 5). This pattern was concordant with previous studies ${ }^{6,15,20,21}$. 
Table 5

Male-relative pair combinations differentiation by each of the 13 rapidly mutating Y-STR markers

\begin{tabular}{|c|c|c|c|c|c|c|c|c|c|}
\hline Markers & $\begin{array}{l}\text { out of all } \\
135 \text { Father } \\
\text { / Son pairs } \\
\text { separated }\end{array}$ & $\begin{array}{l}\text { out of all } 67 \\
\text { Grandfather/ } \\
\text { Grandson } \\
\text { pairs } \\
\text { separated }\end{array}$ & $\begin{array}{l}\text { Out of all } \\
104 \\
\text { Brother/ } \\
\text { Brother } \\
\text { pairs } \\
\text { separated }\end{array}$ & $\begin{array}{l}\text { Out of all } \\
147 \text { Uncle } \\
\text { /Son } \\
\text { pairs } \\
\text { separated }\end{array}$ & $\begin{array}{l}\text { Out of all } \\
08 \text { Great } \\
\text { G. father/ } \\
\text { G. G. son } \\
\text { pairs } \\
\text { separated }\end{array}$ & $\begin{array}{l}\text { Out of all } \\
1901 \text { st- } \\
\text { Cousin/1st- } \\
\text { Cousin } \\
\text { pairs } \\
\text { separated }\end{array}$ & $\begin{array}{l}\text { Out of all } \\
14 \text { Grand } \\
\text { Nephew/ } \\
\text { Uncle } \\
\text { pairs } \\
\text { separated }\end{array}$ & $\begin{array}{l}\text { Out of all } \\
1681 \mathrm{st} \\
\text { Cousin1r/1st } \\
\text { Cousin1r } \\
\text { pairs } \\
\text { separated }\end{array}$ & $\begin{array}{l}\text { Out of all } \\
28 \text { 2nd } \\
\text { cousin } \\
\text { pairs } \\
\text { separated }\end{array}$ \\
\hline DYS526a/b & $0(0 \%)$ & $0(0 \%)$ & $0(0 \%)$ & $0(0 \%)$ & $0(0 \%)$ & $0(0 \%)$ & $0(0 \%)$ & $0(0 \%)$ & $0(0 \%)$ \\
\hline DYS612 & $1(0.74 \%)$ & $5(7.46)$ & $5(4.80)$ & $4(2.72)$ & $0(0 \%)$ & 18(9.47) & $0(0 \%)$ & $14(8.33)$ & $4(14.28)$ \\
\hline DYF399 & 24(17.77\%) & $12(17.9)$ & 19(18.2) & $27(18.3)$ & $1(1 \%)$ & $60(31.5)$ & $4(28.57 \%)$ & $48(28.5)$ & $12(42.85)$ \\
\hline DYS547 & $3(2.222 \%)$ & $2(2.98)$ & $8(7.69)$ & $4(2.72)$ & $0(0 \%)$ & $24(12.6)$ & $2(14.28 \%)$ & 19(11.3) & $5(17.85)$ \\
\hline DYF404 & $3(2.222 \%)$ & $4(5.97)$ & $5(4.80)$ & $1(0.68)$ & $0(0 \%)$ & $8(4.21)$ & $0(0 \%)$ & $6(3.57)$ & $2(7.142)$ \\
\hline DYS626 & $2(1.481 \%)$ & $0(0 \%)$ & $2(1.92)$ & $0(0 \%)$ & $0(0 \%)$ & $0(0 \%)$ & $0(0 \%)$ & $0(0 \%)$ & $0(0 \%)$ \\
\hline DYF403 & $8(5.925 \%)$ & $7(10.4)$ & 12(11.5) & $16(10.8)$ & $0(0 \%)$ & $56(29.4)$ & $0(0 \%)$ & $43(25.5)$ & $13(46.42)$ \\
\hline DYS576 & $4(2.962 \%)$ & $2(2.98)$ & $3(2.88)$ & $10(6.80)$ & $1(1 \%)$ & $8(4.21)$ & $3(21.42 \%)$ & $6(3.57)$ & $2(7.142)$ \\
\hline DYS518 & $5(3.703 \%)$ & $2(2.98)$ & $2(1.92)$ & $6(4.08)$ & $0(0 \%)$ & $6(3.15)$ & $2(14.28 \%)$ & $4(2.38)$ & $2(7.142)$ \\
\hline DYS627 & $1(0.740 \%)$ & $1(1.49)$ & $1(0.96)$ & $3(2.04)$ & $0(0 \%)$ & $4(2.10)$ & $1(7.14 \%)$ & $4(2.38)$ & 1(3.571) \\
\hline DYS570 & $2(1.481 \%)$ & $1(1.49)$ & $1(0.96)$ & $1(0.68)$ & $0(0 \%)$ & $2(1.05)$ & $0(0 \%)$ & $1(0.59)$ & 1(3.571) \\
\hline DYS449 & $1(0.740 \%)$ & $0(0 \%)$ & $1(0.96)$ & $3(2.04)$ & $0(0 \%)$ & $2(1.05)$ & $0(0 \%)$ & $2(1.19)$ & $0(0 \%)$ \\
\hline DYF387 & $5(3.703 \%)$ & $2(2.98)$ & $1(0.96)$ & $1(0.68)$ & $0(0 \%)$ & $8(4.21)$ & $0(0 \%)$ & $6(3.57)$ & $2(7.142)$ \\
\hline
\end{tabular}

\section{Conclusion}

63 endogamous pedigrees which contain 327 individuals were analyzed with classic RM Y-STR panel for differentiating male relatives. Usually conventional Y STRs fails to differentiate between paternal relatives from same pedigree. This RM Y STR panel has provided high level of differentiation between paternally related males and across 4 th meiosis differentiation rate is $>80 \%$. These rapidly mutating $Y$ chromosomal STRs showed the differential ability for both unrelated males and paternal relatives. These markers which are part of RM Y STRs panel also showed high mutation rates. Different commercial companies have proposed different panels of Y Chromosomal STRs to supplement the currently used set of 17 Y-STRs for increased paternal lineage differentiation such as power plex 23 and Yfiler Plus, but none of these showed increase discrimination capacities to differentiated paternal relatives as RM Y STRs have. Moreover, these 13 RM Y STRs give us 29\%-100\% paternal lineages differentiation in most of the populations and $26 \%-85 \%$ in endogamous populations where conventional Y STRs fails to differentiate or have $4 \%$ paternal lineages differentiation power. This high rate of differentiation or individualization using classic RM Y STRs is a great benefit to the field of forensic investigative genetics. Results of this study are concordant with previous studies ${ }^{6,15,16,20,21}$ and have showed considerably increased discrimination power. We also merged this data with previous data (and based on 5176 pairs of men related by $1-20$ meioses), overall differentiation rate was $38.79 \%$ while $Y$-filer differentiation was $9.24 \%$ based on 3864 pairs. Using father-son pair data from the present and previous studies, we also provide updated RM Y-STR mutation rates. However, further studies should be conducted on Pakistani populations, mainly in comparison with commercial kits to further improve the mutation rate information. This study contributes to globally expanding databases for the set of 13 RM Y-STRs.

\section{Ethics Declarations}

\section{Acknowledgments}

We thank all volunteers who provided materials and data for this project specially Muhammad Farhan Khan, Saadia Noreen, Midhat Sulman and Zeenat Salahuddin. This study was financially supported by the Department of Forensic Sciences, University of Health Sciences from departmental funds.

\section{Conflict of interest}

The authors declare that they have no conflict of interest. 
All participants gave their informed consent either orally (in case they could not write) or in writing after the study aims and procedures were carefully explained to them. The study was approved by the ethical review board of the University of Health Sciences, Lahore, Punjab, Pakistan, and in accordance with the standards of the Declaration of Helsinki 1964.

\section{Author contribution}

A.R and A. Adnan developed the idea. S.N., M.J. and R.R, collected the samples. S.N., R.A., R.L., A. Alreyami, I.A, and A. Adnan conducted the experiment. A. Adnan., S.N., A.R., and S.H, analyzed the results. A. Adnan wrote the manuscript and A. Adnan and S.H. revised the manuscript. All authors reviewed the manuscript.

\section{References}

1. Roewer, L. Y chromosome STR typing in crime casework. Forensic Sci. Med. Pathol, 5, 77-84 (2009).

2. Prinz, M., Ishii, A., Coleman, A., Baum, H. J. \& Shaler, R. C. Validation and casework application of a Y chromosome specific STR multiplex. Forensic Sci. Int, 120, 177-188 (2001).

3. Calacal, G. C. et al. Identification of Exhumed Remains of Fire Tragedy Victims Using Conventional Methods and Autosomal/Y-Chromosomal Short Tandem Repeat DNA Profiling. Am. J. Forensic Med. Pathol, 26, 285-291 (2005).

4. Parson, W., Niederstätter, H., Brandstätter, A. \& Berger, B. Improved specificity of Y-STR typing in DNA mixture samples. Int. J. Legal Med, 117, 109-114 (2003).

5. Prinz, M., Boll, K., Baum, H. \& Shaler, B. Multiplexing of Y chromosome specific STRs and performance for mixed samples. Forensic Sci. Int, 85, 209-218 (1997).

6. Adnan, A., Ralf, A., Rakha, A., Kousouri, N. \& Kayser, M. Improving empirical evidence on differentiating closely related men with RM Y-STRs: A comprehensive pedigree study from Pakistan. Forensic Sci. Int. Genet, 25, 45-51 (2016).

7. Adnan, A. et al. Population data of 17 Y-STRs (Yfiler) from Punjabis and Kashmiris of Pakistan. Int. J. Legal Med, https://doi.org/10.1007/s00414-017-1611-9 (2017).

8. Adnan, A., Rakha, A., Lao, O. \& Kayser, M. Mutation analysis at 17 Y-STR loci (Yfiler) in father-son pairs of male pedigrees from Pakistan. Forensic Sci. Int. Genet, https://doi.org/10.1016/j.fsigen.2018.07.001 (2018).

9. Vermeulen, M. et al. Improving global and regional resolution of male lineage differentiation by simple single-copy Y-chromosomal short tandem repeat polymorphisms. Forensic Sci. Int. Genet, 3, 205-213 (2009).

10. Purps, J. et al. A global analysis of Y-chromosomal haplotype diversity for 23 STR loci. Forensic Sci. Int. Genet, 12, 12-23 (2014).

11. Adnan, A. et al. Genetic characterization of Y-chromosomal STRs in Hazara ethnic group of Pakistan and confirmation of DYS448 null allele. Int. J. Legal Med, https://doi.org/10.1007/s00414-018-1962-x (2018).

12. Atif et al. Population data of 23 Y STRs from Manchu population of Liaoning Province, Northeast China. Int. J. Legal Med, https://doi.org/10.1007/s00414-018-1957-7 (2018).

13. Adnan, A. et al. Forensic features and genetic legacy of the Baloch population of Pakistan and the Hazara population across Durand line revealed by Y-chromosomal STRs. Int. J. Legal Med, https://doi.org/10.1007/s00414-021-02591-2 (2021).

14. Adnan, A. et al. Phylogenetic relationship and genetic history of Central Asian Kazakhs inferred from Y-chromosome and autosomal variations. Mol. Genet. Genomics, https://doi.org/10.1007/s00438-019-01617-0 (2019).

15. Ballantyne, K. N. et al. A new future of forensic Y-chromosome analysis: Rapidly mutating Y-STRs for differentiating male relatives and paternal lineages. Forensic Sci. Int. Genet, 6, 208-218 (2012).

16. Ballantyne, K. N. et al. Mutability of Y-chromosomal microsatellites: rates, characteristics, molecular bases, and forensic implications. Am. J. Hum. Genet, 87, 341-353 (2010).

17. Alghafri, R., Goodwin, W., Ralf, A., Kayser, M. \& Hadi, S. A novel multiplex assay for simultaneously analysing 13 rapidly mutating Y-STRs. Forensic Sci. Int. Genet, 17, 91-98 (2015).

18. Goedbloed, M. et al. Comprehensive mutation analysis of $17 \mathrm{Y}$-chromosomal short tandem repeat polymorphisms included in the AmpFISTR® Yfiler® PCR amplification kit. Int. J. Legal Med, 123, 471-482 (2009).

19. Adnan, A. et al. Evaluation of 13 rapidly mutating Y-STRs in endogamous Punjabi and Sindhi ethnic groups from Pakistan. Int. J. Legal Med, 133, 799-802 (2019).

20. Rakha, A. et al. Discriminating power of rapidly mutating Y-STRs in deep rooted endogamous pedigrees from Sindhi population of Pakistan. Leg. Med, 34, 17-20 (2018).

21. Ballantyne, K. N. et al. Toward Male Individualization with Rapidly Mutating Y-Chromosomal Short Tandem Repeats. Hum. Mutat, 35, 10211032 (2014). 
22. Ali, N., Coulson-Thomas, Y. M., Norton, A. L., Dixon, R. A. \& Williams, D. R. Announcement of population data: genetic data for 17 Y-STR AmpFeSTR® YfilerTM markers from an immigrant Pakistani population in the UK (British Pakistanis). Forensic Sci. Int. Genet, 7, e40-42 (2013).

23. Perveen, R., Shahid, A. A., Shafique, M., Shahzad, M. \& Husnain, T. Genetic variations of 15 autosomal and 17 Y-STR markers in Sindhi population of Pakistan. Int. J. Legal Med, https://doi.org/10.1007/s00414-017-1544-3 (2017).

24. Tabassum, S., Ilyas, M., Ullah, I., Israr, M. \& Ahmad, H. A comprehensive Y-STR portrait of Yousafzai's population. Int. J. Legal Med, 131, 1241-1242 (2017).

25. Lee, E. Y. et al. Analysis of 22 Y chromosomal STR haplotypes and Y haplogroup distribution in Pathans of Pakistan. Forensic Sci. Int. Genet, 11, 111-116 (2014).

26. Javed, F. et al. Male individualization using 12 rapidly mutating Y-STRs in Araein ethnic group and shared paternal lineage of Pakistani population. Int. J. Legal Med, 132, 1621-1624 (2018). 